\title{
Wide-Area Power Oscillation Damper Implementation and Testing in the Norwegian Transmission Network
}

\author{
K. Uhlen, Member, IEEE, L. Vanfretti, Member, IEEE, M. M. de Oliveira, Member, IEEE \\ A. B. Leirbukt Member, IEEE, V. H. Aarstrand, and J. O. Gjerde, Member, IEEE
}

\begin{abstract}
This article reports the results from the implementation and testing of a Wide-Area Power Oscillation Damper (WAPOD) controlling a 180 Mvar TCR Static Var Compensator (SVC) installed in the Hasle substation of Norwegian $420 \mathrm{kV}$ transmission grid. The WAPOD uses voltage phase angle signals from two distant locations in the Norwegian grid as inputs to the damping controller. The damping controller modulates the voltage reference set point used by the SVC's voltage controller, thereby creating a damping effect. The WAPOD is an extension to the existing Power Oscillation Damping (POD) controller that uses local measurements. A switch-over logic allows for the use of no damping control, local damping control or wide-area control.

Field tests were performed during November 2011, and involved the disconnection and re-connection of a $420 \mathrm{kV}$ transmission line. The performance of the WAPOD is compared to that of state-of-the-art local Phasor POD, and when no damping control is enabled. The testing results show that the WAPOD performed satisfactorily and according to the design expectations. These results show that the potential flexibility of the WAPOD to choose, among the different PMU signals, those that have the good observability of inter-area modes can be an advantage to the use of local feedback signals for damping control, as it is current practice today. Further testing of this WAPOD with other PMU signals from locations with stronger observability will be helpful to illustrate the advantage of this flexibility.
\end{abstract}

Index Terms-Wide-Area Measurement Systems, Wide-Area Monitoring Systems, Wide-Area Control Systems, Wide-Area Power Oscillation Damping, Nordic Power System

\section{INTRODUCTION}

$\mathbf{T}$ He Nordic synchronous grid is a group of AC interconnected networks coupling Norway, Sweden, Finland, and Eastern Denmark, and spanning large geographical distances in Northern Europe. The long corridors in the Nordic grid have to transport, at different instances, substantial power transfers over distances of 2,000 km [1]. Due to the nature of such power transfers, the Nordic grid is at times limited

Manuscript submitted to the IEEE PES General Meeting 2012.

Invited Paper for the Panel Session: "Synchrophasor Measurement Applications in Power Industry to Enhance Power System Reliability", IEEE PES General Meeting 2012, San Diego, CA.

This work was supported in part by the Norwegian Research Council (NFR).

K. Uhlen is with the Department of Electrical Power Engineering, Faculty of Information Technology, Mathematics, and Electrical Engineering, Norwegian University of Science and Technology (NTNU), O. S. Bragstads plass 2E, N7034 Trondeim, Norway. E-mail: kjetil.uhlen@ntnu.no.

L. Vanfretti is with the Electric Power Systems Division, School of Electrical Engineering, KTH Royal Institute of Technology, Teknikringen 33, SE-100 44, Stockholm, Sweden. E-mail: luigiv@kth.se. L. Vanfretti is supported by the STandUP for Energy collaboration initiative and the KTH School of Electrical Engineering.

M. M. de Oliveira is with ABB FACTS, SE-721, Västerås, Sweden. E-mail: marcio.oliveira@se.abb.com.

A. Leirbukt is with ABB Power Systems, Oslo, Norway. E-mail: albert.leirbukt@no.abb.com.

V.H. Aarstrand and J.O. Gjerde are with the Norwegian TSO, Statnett SF, Research and Development, Hysebybakken 28 B, N-0302 Oslo, Norway. Email: jan.gjerde@ statnett.no,vemund.halmo.aarstrand@enfo.no. by stability constraints related to poor damping of interarea oscillations [2], [3], [4], particularly during high power exports from Norway and Finland into Sweden. Statnett SF, the Norwegian transmission system operator, has worked since 2005 in the development, implementation and deployment of an integrated Wide-Area Monitoring System (WAMS) [5], [3], [6], which can be used to continuously monitor power oscillations and alarm operators when they reach undesirable levels [7]. To further improve system damping, and thereby increase power transfer capabilities, Statnett has made efforts in the design, and now reported in this paper, the implementation and testing of Wide-Area Control Systems (WACS) for Wide-Area Power Oscillation Damping [8], [9].

This article reports the results from the implementation and testing of a Wide-Area Power Oscillation Damper (WAPOD) controlling a 180 Mvar TCR Static Var Compensator (SVC) installed in the Hasle substation of Norwegian $420 \mathrm{kV}$ transmission grid. The WAPOD uses voltage phase angle signals from two distant locations in the Norwegian grid as inputs to the damping controller. The damping controller modulates the voltage reference set point used by the SVC's voltage controller. This signal modulates the SVC voltage reference to generate reactive power compensation capable of damping enhancement. Field tests were performed during November 2011, and involved the disconnection and re-connection of a $420 \mathrm{kV}$ transmission line. The performance of the WAPOD is compared to that of the Local Phasor POD, and when no damping control is enabled. The testing results show that the WAPOD performed satisfactorily and accordingly to the design expectations. These test results show that the potential flexibility of the WAPOD to choose, among the different PMU signals, those that have the good observability of inter-area modes can be an advantage to the use of local feedback signals for damping control, as it is the current practice today.

The remainder of this article is organized as follows. Section II gives a brief description of the Nordic power system, its inter-area modes, PMU installations, and the location of the SVC which is subject to WAPOD control. Section III gives an overview of Statnett's integrated Wide-Area Monitoring and Control Platform and its implementation. In Section IV the control scheme used to feed either wide-area, local or no damping control signals into the SVC at Hasle is described, while in Section $\mathrm{V}$ the performed tests and corresponding measurements are presented. Section VI discusses the damping controllers' performance by analyzing the resulting feedback signals from local and wide-area measurements, and the resulting reactive power compensation from the SVC. Finally, conclusions are drawn in Section VII. 


\section{The Nordic Power System}

The Nordic synchronous grid comprises the inter-connected power systems of Norway, Sweden, Finland, and Eastern Denmark. Western Denmark is connected to the synchronous system of continental Europe, while Iceland operates isolated. Fig. 1 shows the main transmission corridors of the Nordic Power system, along with the location of the installation of different PMU devices and the location of one of the SVCs installed in Norway [3]. Notice that the geographical distances of the Nordic transmission grid are long, and in different instances power transfers from Finland to Sweden may have to travel through the AC grid for about 2,000 km [1].

Due to the nature of power flow transfers, the synchronous Nordic grid is at times limited by stability constraints related to poor damping of inter-area oscillations, particularly during high power exports from Norway and Finland into Sweden. Detailed large-scale model small-signal analysis studies [2] and evidence from measurements [3], [4], show that the Nordic grid has several dominant oscillatory modes, including interarea modes and local modes. The most dominating oscillatory modes identified in [2] are shown in Table I, which correspond to one high loading operating condition. The frequency and damping of the oscillatory modes depends on the actual operation point and the power system configuration, thus they will show significant variations over different operating scenarios [3], [4], [10].

To improve the power transfer capability of the Norwegian grid which are limited by small-signal stability constraints, Statnett has taken steps in two major directions: (i) the implementation of a Wide-Area Monitoring System for continuously providing estimates and alarms of poorly damped oscillations; and (ii) the installation of three new Static Var Compensators (SVCs) that can be used for oscillation damping [7], [11]. The following sections show the implementation and testing of a Wide-Area Control System and a Wide-Area Power Oscillation Damper (WAPOD) that use synchrophasor data as control input signals for damping purposes.

\section{Wide-Area Monitoring And Control Platform IMPLEMENTATION}

Statnett SF, the Norwegian transmission system operator, has worked since 2005 in the development, implementation and deployment of an integrated wide-area monitoring and control system that exploits synchronized phasor measurement

TABLE I

DOMINATING OSCILLATORY MODES IN THE NORDIC GRID COMPUTED FROM MODAL ANALYSIS [2]

\begin{tabular}{|c|c|l|}
\hline Frequency $(\mathrm{Hz})$ & Damping (\%) & Observability (Mode Shape) \\
\hline \hline 0.33 & 4.34 & $\begin{array}{l}\text { Inter-area mode, observable as os- } \\
\text { cillations between Finland and } \\
\text { Southern Norway }\end{array}$ \\
\hline 0.48 & 2.34 & $\begin{array}{l}\text { Inter-area mode, observable as os- } \\
\text { cillations between Southern Nor- } \\
\text { way and Sweden/Denmark }\end{array}$ \\
\hline 0.54 & 2.21 & $\begin{array}{l}\text { Local area mode, observable in } \\
\text { Northern Norway }\end{array}$ \\
\hline 0.76 & 1.40 & $\begin{array}{l}\text { Local area mode, observable in } \\
\text { Western Norway }\end{array}$ \\
\hline
\end{tabular}

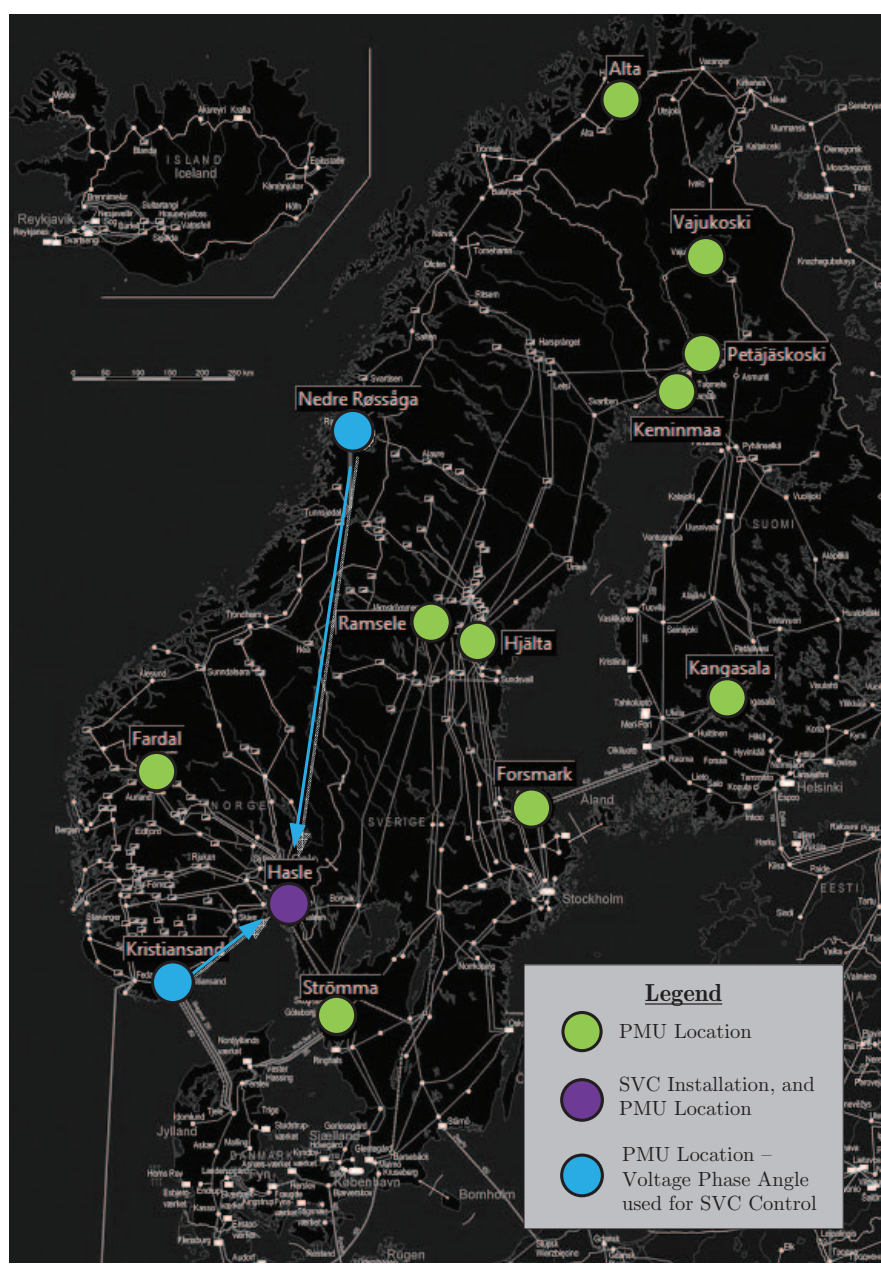

Fig. 1. The Nordic Power System, PMU Installations and SVC Location

data [3], [5]. The general architecture of this WAMS/WACS system is shown in Fig. 2. As with other WAMS/WACS systems [12], Statnett's own architecture consists of a data acquisition layer, a data management layer, and an applications layer.

The data acquisition layer interfaces the actual physical power components, such as bus bars and power lines, with the WAMS/WACS system. It consists of synchronized phasor measurement devices (PMUs) and other Intelligent Electronic Devices (IEDs) such as Digital Fault Recorders (DFRs) and Remote Terminal Units (RTUs). In Statnett the data management layer includes the integration of SCADA data and other lower resolution data through its data management layer [6]. Here a phasor data concentrator collects and sorts data into a single time-synchronized data set, assembling data from other sources at the same time.

Finally, the system includes an application layer, here the data management layer provides measurements that applications can harvest. For monitoring purposes, Statnett has developed its own Labview Analysis Application [6]. This WAMS system has been described previously in [3].

The PDC receives PMU measurements and forwards synchronized data to the Labview WAMS application. Additionally, as illustrated in Fig. 5b, the PDC forwards the chosen voltage phasors to the SVC control system (see details in the 


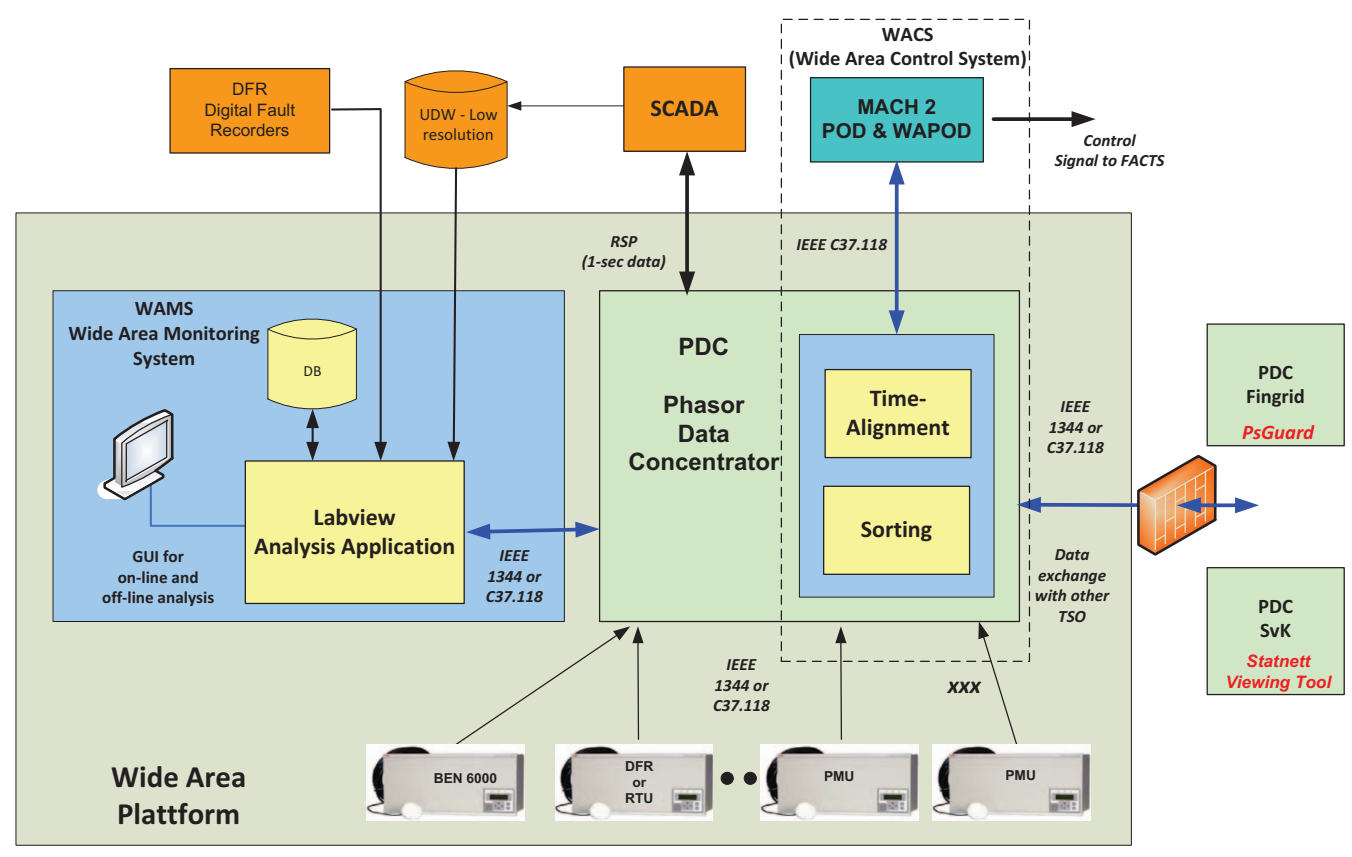

Fig. 2. Statnett's Integrated Wide-Area Monitoring and Wide-Area Control System

next section), in this case $\mathrm{ABBs} \mathrm{MACH} 2$ controller, forming an ad hoc Wide-Area Control System (WACS). The MACH 2 controller calculates the relative voltage phase angle difference and makes use of this signal in a new WAPOD damping controller.

\section{SVC Control SCHEME For Wide-Area Signals}

The SVC installed at the Hasle substation is a twelvepulse 180 Mvar TCR Static Var Compensator, whose intended purpose is voltage control (reactive power compensation) as well as for the damping of inter-area oscillations in the Nordic grid. The SVC control scheme has been modified to include a "Switch-Over Logic" that allows for the use of either manual control, local POD, or WAPOD, as shown in Fig. 3. The blocks highlighted in light blue correspond to the original local POD control and the green blocks correspond to the modifications made to the control scheme to allow for a flexible selection of the desired damping control mode, i.e. local or wide-area. Both local and wide-area POD functions employ the phasor estimation method [13] for extracting oscillations at the modes of interest.

Initially, this SVC was designed to use adjacent line power flow measurements, $P_{i j}(t)$, as an input for a local Phasor Power Oscillation Damper (POD), to generate feedback signal. This feedback signal can now be enabled or disabled by the Switch-Over Logic that chooses between manual control, local POD or WAPOD. When local POD control is used the input signals to the compensator are line active power measurements, $P_{i j}(t)$, and when WAPOD control is used the input signals to the compensator are bus voltage angle differences, $\Delta \theta(t)$. One important feature of the switch-over logic is the automatic transfer to the Local POD in case the WAPOD is active but communication with the PDC or PMUs is lost for a long interval of time.

With either local POD or WAPOD, the feedback signal, $\Delta V$, is compared to a voltage set point, $V_{r e f}$, to produce an

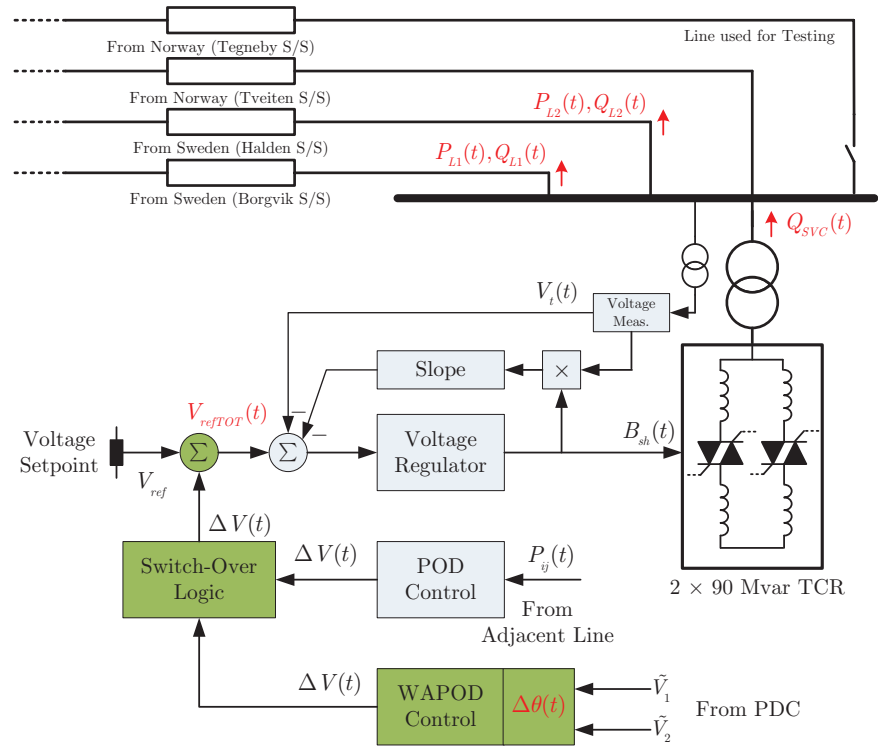

Fig. 3. SVC Control Scheme using Local Measurements and WideArea Measurements. $\tilde{V}_{1}$ and $\tilde{V}_{2}$ correspond to voltage phasors measured at Kristiansand and Nedre Røssåga, respectively.

error signal, $V_{\text {refTOT }}(t)$, that modulates the voltage regulator of the SVC. This in turns varies the shunt impedance, $B_{s h}(t)$, by modulating the firing pulses to the TCRs resulting in a reactive power compensation, $Q_{S V C}(t)$, capable of damping the power swings. The effect of this compensation can be observed not only in the actual damping of the power swings $P_{L 1}(t)$ and $P_{L 2}(t)$ in the lines connecting the Hasle substation, but also in the reactive powers $Q_{L 1}(t)$ and $Q_{L 2}(t)$ through the lines and the terminal bus voltage magnitudes.

\section{Wide-Area Power Oscillation Damper Testing}

Several tests were conducted to assess the performance of the WAPOD controller for damping inter-area oscillations. 


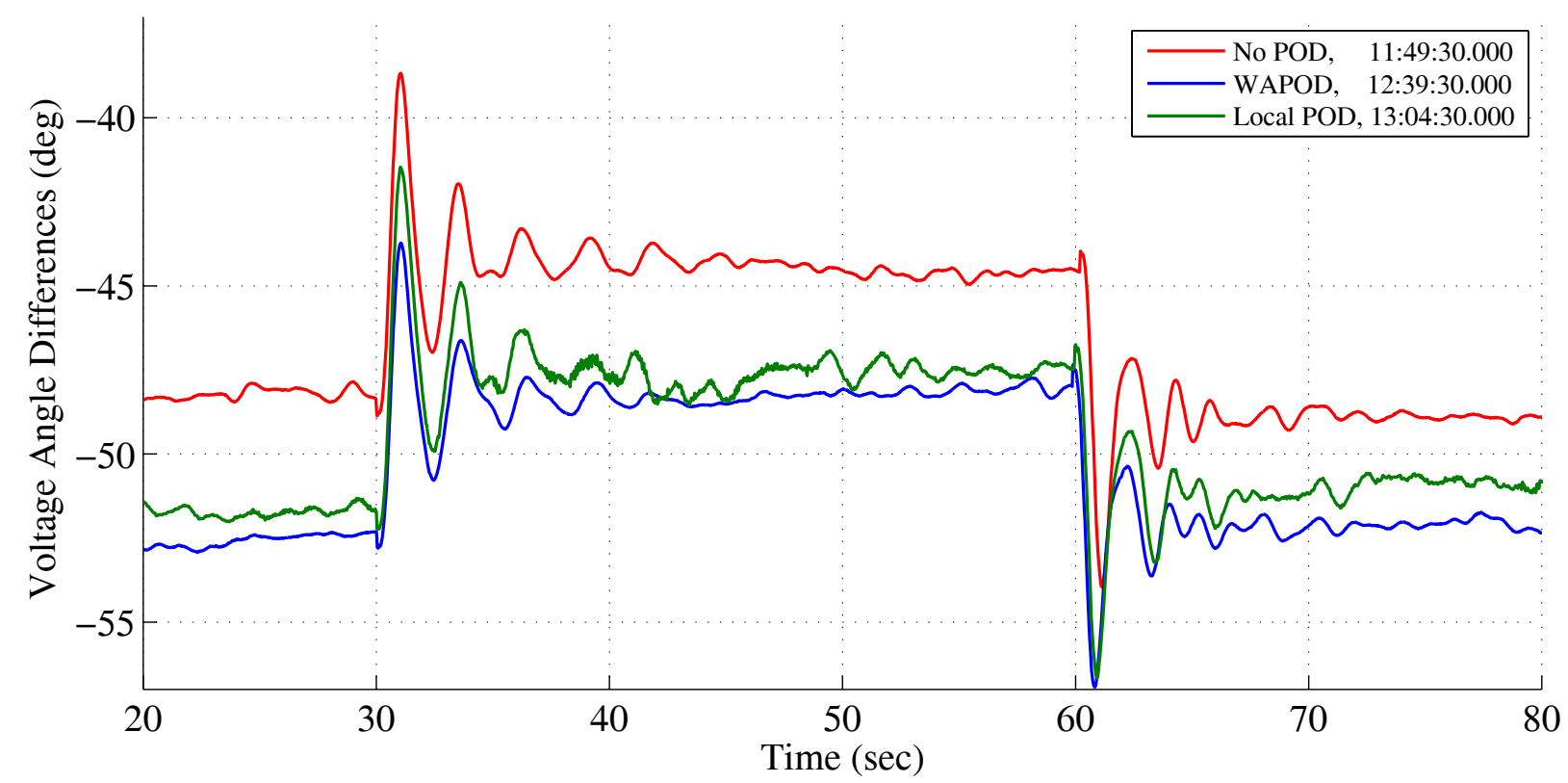

(a) $\Delta \theta$ between Kristiansand and Nedre Røssåga

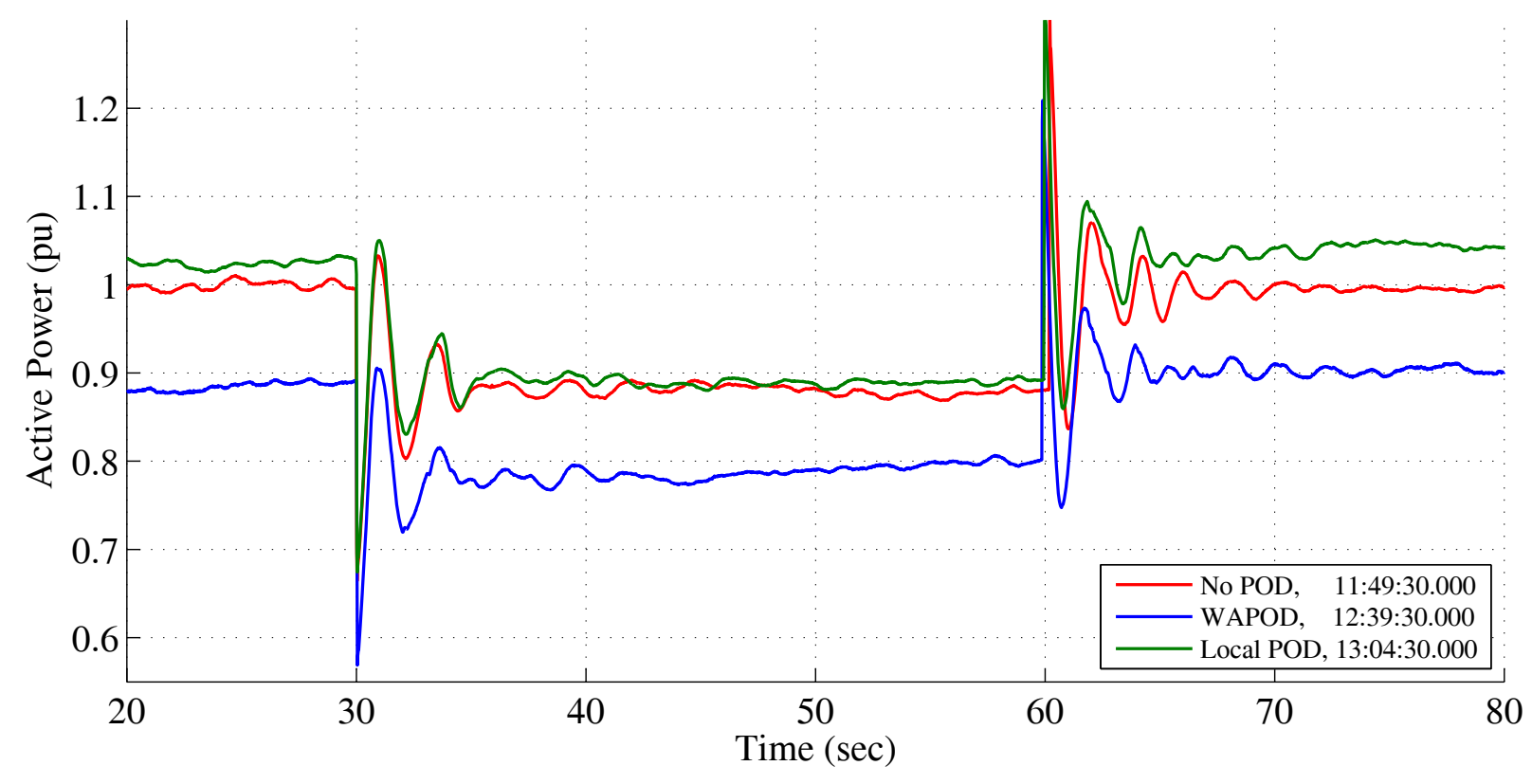

(b) $P_{L 1}+P_{L 2}$ at Hasle

Fig. 4. Voltage Angle Differences and Active Power Flows during the Testing of the WAPOD

Only three of these tests are outlined below. The tests involved the disconnection and re-connection of a $420 \mathrm{kV}$ line connected in the vicinity of the Hasle substation, and were carried out with the following control configurations:

- No POD: no damping control was enabled (manual control), the SVC was operating only under voltage regulation.

- WAPOD: wide-area power oscillation damping control, using voltage angle differences, $\Delta \theta$, as control input. The controller was tuned to damp the $0.48 \mathrm{~Hz}$ mode shown in Table I.
- Local POD: local power oscillation damping control, using the power flow of an adjacent line to the SVC, $P_{i j}$, as control input. The controller was tuned to damp the $0.48 \mathrm{~Hz}$ mode shown in Table I, matching the gain so that it was similar to the WAPOD controller. Note that this Phasor POD can also be tuned to damp multiple modes simultaneously.

Figure $4 \mathrm{a}$ shows the voltage angle difference, $\Delta \theta$, between Kristiansand and Nedre Røssåga during the tests, while Fig. $4 \mathrm{~b}$ shows the active power flows, $P_{L 1}+P_{L 2}$, in the Hasle 
corridor $^{1}$ to Sweden. The disconnection of the transmission line occurred at $t \approx 30$ seconds, while the re-connection occurred at $t \approx 60$ seconds. It should be noted that the tests were performed at different loading conditions, which is inevitable as changes in power flows are perennial. However, the loading through the Hasle corridor was similar during each of the tests.

The WAPOD performed as intended and according to the expectations, as it can be seen from Fig 4b, the system damping is improved compared to the case of No POD control. With this limited number of tests it is not possible to conclude whether a WAPOD will perform more satisfactorily than the current local measurement-based Phasor POD. This is dependent upon several factors including:

(i) The actual tuning of the compensators [8], [9],

(ii) The availability of measurements with good "modal content [15]" and

(iii) The power system configuration and disturbance (outage). Nevertheless, the virtue of the WAPOD lays in its potential flexibility to choose, among the different available PMU signals, those that have dominant inter-area content as control inputs.

It is interesting to note from Fig. 4a that specially during the disconnection tests the WAPOD control has a larger "widearea" impact than that of the local POD, as it can be evidenced by the damping of the $0.48 \mathrm{~Hz}$ mode seen in the blue trace compared to that of the green trace. This is relevant as the $\Delta \theta$ signal was used for WAPOD control. Also note that when the system is under No POD or Local POD control, there is a very relevant amount of modal content for not only the 0.48 $\mathrm{Hz}$ mode, but also the $0.33 \mathrm{~Hz}$ mode, in the $\Delta \theta$ signals.

As it can be observed from both Figs. $4 \mathrm{a}$ and $4 \mathrm{~b}$, the 0.33 $\mathrm{Hz}$ mode is also present in the signals for all of the tests, although with a lower activity than the $0.48 \mathrm{~Hz}$ mode. Future testing of the WAPOD could reveal interesting results if they include the tuning of the controller for simultaneous damping of both the $0.33 \mathrm{~Hz}$ and $0.48 \mathrm{~Hz}$ modes.

The output function of the POD regulators are released when the phasor estimation algorithm detects a certain amplitude of the oscillating component from the extracted signal (at the target frequency). For the Local POD, this level is $50 \mathrm{MW}$, while $0.02 \mathrm{rad}$. are used for the WAPOD. When the line is disconnected, the active power variation changes abruptly (Fig.4b) while the variations in the voltage phase angle difference is "smoother" (Fig. 4a). Thus, the local POD reaches its threshold level faster than the WAPOD.

\section{Damping Controller Performance USing WIDE-AREA AND LOCAL SIGNALS}

As mentioned in the previous section, there are three major factors affecting the response of both damping controllers, Local POD or WAPOD. To explicate these points Figs. 5 and 6 show the error signal driving the SVC's voltage regulator,

\footnotetext{
${ }^{1}$ The 'Hasle corridor' is a major power transfer path between southern Norway and Sweden. At times this corridor is a frequent bottleneck for power transfer between Norway and Sweden, and power exports to Sweden are affected (see [14]).
}

$V_{\text {refTOT }}$, and the reactive power compensation produced by the SVC, $Q_{S V C}$ (see Fig.3 for the location of these signals within the control scheme).

Notice from Fig. 5a that the initial response of the local POD reacts to the sudden change in power flow, while the WAPOD responds to the (remote) change in the voltage angle differences in Fig. 4a. This underlines the fact that the best response depends on the power system configuration and disturbance itself. There is no guarantee that any disturbance will cause a reaction in the local measurements that can provide a good damping effect by the POD $^{2}$. The wide-area measurements are, to a less degree, influenced by the actual disturbance, and contain a richer "modal content" involving the inter-area swings. As shown in Fig.4a, the time response of the voltage angle difference contains a rich inter-area oscillation content and are able to produce a signal that provides a good damping effect through the WAPOD.

It is important to correlate the responses in Fig. 5a and 6a. Note that $V_{\text {refTOT }}$ of the local POD responds first (at $t \approx 2 \mathrm{~s}$ ) and saturates to its maximum value initially, while the WAPOD signal stays constant and reacting about $0.7 \mathrm{sec}$ after the line outage $(t=2 \mathrm{sec})$. As a result, the reactive power consumed by the thyristor controlled reactors, $Q_{S V C}$, shown in Fig. 5b, is affected. For the local POD, $Q_{S V C}$ is delayed for about 0.5 seconds compared to the WAPOD, this is due to the fact that the signals $V_{\text {refTOT }}$ show in Fig. 5a, depart in different directions.

This is even more prominent during the reconnection tests, shown in Fig. 6. For these tests the difference in initial responses after the line outage is show in Fig. 6a for $V_{\text {refTOT, }}$, and Fig. $6 \mathrm{~b}$ for $Q_{S V C}$. Notice that the control signals also depart in different directions, but for the local POD $V_{\text {refTOT }}$ shows a sudden drop, prompting an almost immediate response by the SVC as depicted in Fig. 6b. On the other hand, the WAPOD signal first saturates at its maximum value and then the damping part operates from the second power swing. Note that for damping purposes, the phase shift of the WAPOD will be correct all of the time.

End-to-end latency, due to communication and processing of the synchrophasor data used as input signals to the WAPOD, was negligible and normally within 30 milliseconds. Nevertheless, there were occasional samples, which for unknown reasons, were delayed up to 200-300 milliseconds. For power oscillation damping purposes, these sporadic delays do not represent a major issue. Furthermore, if the delay becomes longer than a pre-set threshold, an automatic switch-over to Local POD will take place.

\section{CONCLUSIONS}

This article described the implementation and testing of a Wide-Area Power Oscillation Damper (WAPOD) controlling a twelve-pulse 180 Mvar TCR Static Var Compensator (SVC) installed in the Hasle substation of Norwegian $420 \mathrm{kV}$ transmission grid. The WAPOD uses voltage phase angle signals

\footnotetext{
${ }^{2}$ In this case, a line outage near the Hasle corridor did have an effect in the adjacent power flow, $P_{L 1}+P_{L 2}$, due to the vicinity of the measurement locations.
} 


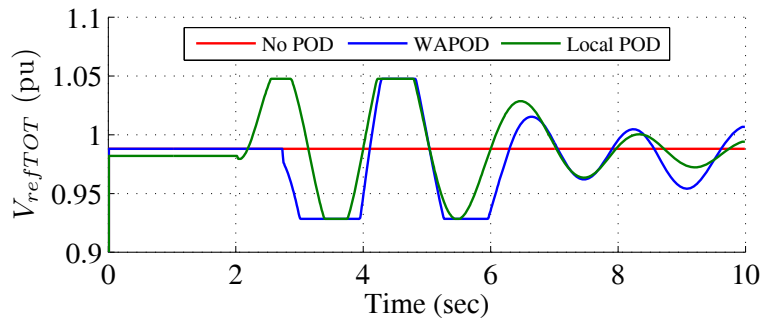

(a) $V_{\text {refTOT }}$ signal fed into the SVC Voltage Regulator

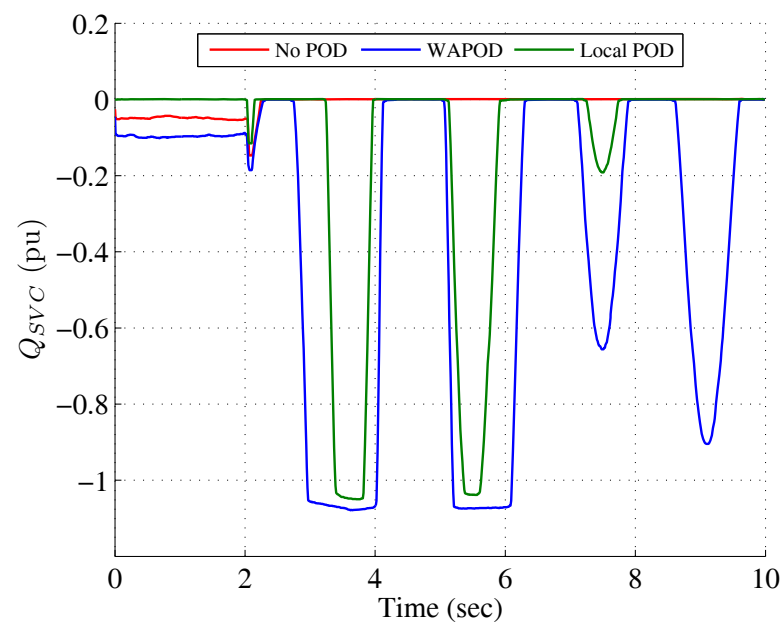

(b) Reactive Power compensation by the SVC

Fig. 5. $\quad V_{\text {refTOT }}$ Damping Signals and $Q_{S V C}$ during disconnection tests.

from two distant locations in the Norwegian grid. The filed tests reported in this article show that the WAPOD performed satisfactorily and accordingly to the design expectations.

With the limited number of tests carried out so far, it is not possible to conclude whether a WAPOD will perform more satisfactorily than the current local measurement-based Phasor POD. This is dependent upon several factors including: (i) the actual tuning of the compensators, (ii) the availability of measurements with good "modal content", and (iii) the power system configuration and disturbance (outage). Nevertheless, the testing results show that the potential flexibility of the WAPOD to choose, among the different PMU signals, those that have the good observability of inter-area modes can be an advantage to the use of local feedback signals for damping control, as it is the current practice today. Further testing of this WAPOD with other PMU signals from locations with stronger observability will be helpful to illustrate the advantage of this flexibility.

\section{REFERENCES}

[1] T. Rauhala, K. Saarinen, M. Latvala, M. Laasonen, and M. Uusitalo, "Applications of phasor measurement units and wide-area measurement system in Finland," in IEEE Trondheim PowerTech, 2011, june 2011, pp. $1-8$.

[2] K. Uhlen, S. Elenius, I. Norheim, J. Jyrinsalo, J. Elovaara, and E. Lakervi, "Application of linear analysis for stability improvements in the nordic power transmission system," in IEEE Power Engineering Society General Meeting, 2003, vol. 4, july 2003, p. 4 vol. 2666.

[3] K. Uhlen, L. Warland, J. Gjerde, O. Breidablik, M. Uusitalo, A. Leirbukt, and P. Korba, "Monitoring amplitude, frequency and damping of power system oscillations with PMU measurements," in 2008 IEEE Power and

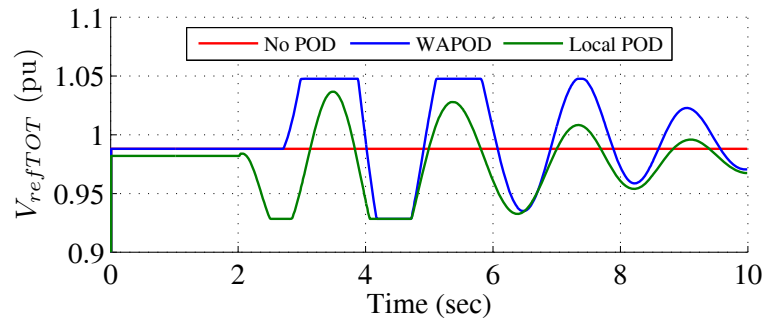

(a) $V_{\text {refTOT }}$ signal fed into the SVC Voltage Regulator

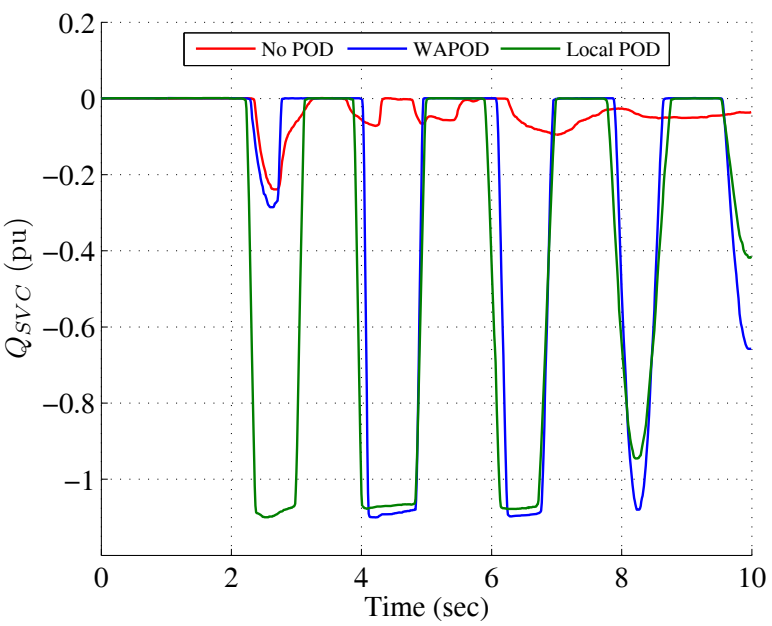

(b) Reactive Power compensation by the SVC

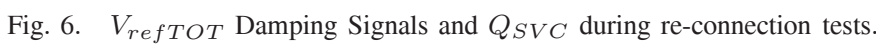

Energy Society General Meeting - Conversion and Delivery of Electrical Energy in the 21st Century., july 2008, pp. $1-7$.

[4] L. Vanfretti, R. García-Valle, K. Uhlen, E. Johansson, D. Trudnowski, J. Pierre, J. Chow, O. Samuelsson, J. Ø andstergaard, and K. Martin, "Estimation of Eastern Denmark's electromechanical modes from ambient phasor measurement data," in 2010 IEEE Power and Energy Society General Meeting, july 2010, pp. $1-8$.

[5] A. Leirbukt, J. Gjerde, P. Korba, K. Uhlen, L. Vormedal, and L. Warland, "Wide Area Monitoring Experiences in Norway," in 2006 IEEE PES Power Systems Conference and Exposition, 2006. PSCE '06., nov 2006, pp. $353-360$.

[6] A. Leirbukt, O. Breidablik, J. Gjerde, P. Korba, K. Uhlen, and L. Vormedal, "Deployment of a SCADA integrated wide area monitoring system," in 2008 IEEE/PES Transmission and Distribution Conference and Exposition: Latin America, aug. 2008, pp. 1 -6.

[7] P. Korba and K. Uhlen, "Wide-area monitoring of electromechanical oscillations in the nordic power system: practical experience," IET Generation, Transmission Distribution, vol. 4, no. 10, pp. 1116 -1126, october 2010.

[8] E. Johansson, K. Uhlen, A. Leirbukt, P. Korba, J. Gjerde, and L. Vormedal, "Coordinating power oscillation damping control using wide area measurements," in Power Systems Conference and Exposition, 2009. PSCE '09. IEEE/PES, march 2009, pp. $1-8$.

[9] N. R. Chaudhuri, A. Domahidi, B. Chaudhuri, R. Majumder, P. Korba, S. Ray, and K. Uhlen, "Power oscillation damping control using widearea signals: A case study on Nordic equivalent system," in 2010 IEEE PES Transmission and Distribution Conference and Exposition, april 2010, pp. $1-8$.

[10] L. Vanfretti, L. Dosiek, J. W. Pierre, D. Trudnowski, J. H. Chow, R. Garca-Valle, and U. Aliyu, "Application of ambient analysis techniques for the estimation of electromechanical oscillations from measured pmu data in four different power systems," European Transactions on Electrical Power, vol. 21, no. 4, pp. 1640-1656, 2011. [Online]. Available: http://dx.doi.org/10.1002/etep.507

[11] T. Rauhala, J. Jyrinsalo, and H. Kuisti, "Enhancing the transmission capability using FACTS: The Finnish experience," in 9th IET International Conference on AC and DC Power Transmission, 2010., oct. 2010, pp. $1-5$. 
[12] J. Hauer and J. DeSteese, "Descriptive Model of Generic WAMS," Pacific Northwest National Laboratory,Richland, WA., Tech. Rep., 2007.

[13] L. Ängquist and C. Gama, "Damping algorithm based on phasor estimation," in IEEE Power Engineering Society Winter Meeting, vol. 3, 2001, pp. $1160-1165$ vol.3.

[14] W. Quaintance, K. Uhlen, D. Julian, J. Gjerde, K. Vu, and L. Vormedal, "Raising energy transfer in corridors constrained by voltage instabilitystatnett case," in IEEE Power Engineering Society Summer Meeting, vol. 4, 2000, pp. $2021-2026$.

[15] L. Vanfretti and J. Chow, "Analysis of power system oscillations for developing synchrophasor data applications," in 2010 iREP Symposium - Bulk Power System Dynamics and Control (iREP) - VIII (iREP), aug. 2010, pp. $1-17$.

Kjetil Uhlen (M'95) was born in 1961. He received the Sivilingeniør degree from the Norwegian Institute of Technology in 1986 and a Ph.D. degree in control engineering from the same institute in 1994. Since 1987 he has worked at SINTEF Energy Research in Trondheim, as team leader and senior research scientist. From 2009 he is Professor in Power Systems at NTNU, the Norwegian Institute of Science and Technology.

Luigi Vanfretti (Student Member '03, M'10) is an Assistant Professor at the Electric Power Systems Division, School of Electrical Engineering, KTH Royal Institute of Technology, Stockholm, Sweden. He received his M.S. in 2007 and Ph.D. in 2009, both in Electric Power Engineering, from Rensselaer Polytechnic Institute, Troy, NY, USA. His research interests are currently in the area of PMU data applications for dynamics, stability and control of power systems.

Marco Magalhães de Oliveira (Student Member '91, M'01) was born in Rio de Janeiro, Brazil, in 1967. He obtained the Ph.D. degree in the area of high power electronics from KTH Royal Institute of Technology, Stockholm, Sweden, in 2000. In the same year, he joined ABB FACTS in Västerås, Sweden, where he has worked on system design, control system tests and studies of reactive power compensation tenders/projects and R\&D activities. In 2007, he was appointed ABB specialist in analysis and control of FACTS devices.
Albert Leirbukt (M'98) received his MSc in Electrical Engineering from the Norwegian University of Science and Technology in 1997. He has led several projects in research and development, as well as energy consulting. His current research interests include smart grids, FACTS and HVDC. He is currently employed with ABB Power Systems in Norway.

Vemund Halmø Aarstrand received the Sivilingeniør degree from the Norwegian University of Science and Technology in 1999, with a diploma in Nonlinear optics written at École Polytechnique. He has since had varied experience as system developer, high school teacher, weather systems analyzer and marine warranty surveyor. The last five years he has increasingly been involved in smart grid related projects as a consultant at Statnett, with focus on PMU software. He is currently employed at Enfo Technology AS in Oslo, Norway, as a senior systems developer.

Jan Ove Gjerde was born in Hareid in 1958. He received a MSc in electrical engineering from The Norwegian Institute of Technology in 1983. He has long experience in research and development from the energy sector, both as an senior research scientist at Sintef Energy Research and as a department head at ABB Corporate Research, Power System and Components Department. He is running his own consultant company since 2005. Currently he is Vice President of R\&D at Statnett responsible for developing R\&D strategies focusing on new concepts for Risk Management, WAMS, WACS and WAPS, and the overall R\&D Programs at Statnett. 